\title{
Pengaruh Variasi Holding Temperature dan Holding Time pada Post Weld Heat Treatment Terhadap Struktur Mikro dan Distribusi Kekerasan Hasil Pengelasan Material Bisclad 600 Dengan Metode Smaw Di PT. Holcim Indonesia
}

\author{
Amy Reza Andrea, Wikan Jatimurti, Lukman Noerrochim \\ Departemen Teknik Material, Fakultas Teknologi Industri, Institut Teknologi Sepuluh Nopember (ITS) \\ e-mail: lukman@mat-eng.its.ac.id
}

\begin{abstract}
Abstrak-Pengelasan terhadap material Bisclad 600 telah dilakukan dengan menggunakan metode pengelasan SMAW. Spesimen pengelasan dibuat dengan ukuran $100 \mathrm{~mm} \times 100 \mathrm{~mm} \times$ $10 \mathrm{~mm}$ sebanyak 6 spesimen. Proses pengelasan dilakukan dengan menggunakan parameter arus $100 \mathrm{~A}$, tegangan 12 volt, dan kecepatan $100 \mathrm{~mm} / \mathrm{s}$. pengelasan dilakukan dengan dua jenis filler metal yaitu E7018-H4R untuk bagian base metal dan elektroda Ni-C1 untuk bagian hardfacing. Setelah itu, spesimen diberi perlakuan panas pada temperatur $650^{\circ} \mathrm{C}$ dan $750^{\circ} \mathrm{C}$ dengan waktu tahan sebesar 1 jam, 2 jam, dan 3 jam. Material kemudian diuji dengan liquid penetrant test, metalografi, dan kekerasan. Hasil pengujian menunjukkan adanya fasa $\gamma$ Nickel pada daerah weld metal . Pada daerah HAZ dan base metal struktur mikro yang diamati adalah perlit dan dua karbida hasil transformasi isothermal dengan jenis sama. Kekerasan area las terendah dicapai oleh weld metal sedangkan kekerasan pada daerah HAZ dan base metal lebih tinggi dibanding dengan weld metal dengan distribusi kekerasan beragam.
\end{abstract}

Kata Kunci-AWS, Base Metal, HAZ, Karbida, Weld Metal.

\section{PENDAHULUAN}

B ISCLAD 600 merupakan plat hasil cladding antara baja karbon rendah dan High Chromium White Cast Iron. High Chromium White Cast Iron digunakan sebagai material pelapis permukaan untuk menghindari terjadinya aus pada equipment perusahaan.. Penggunaan paduan besi dengan jenis ini biasanya ditujukan untuk melapisi Drag Line, Shovel, Hopper, Chute, pelat peluncur, deflector, pipa sluri, dan pipa debu yang kebanyakan terdapat pada industri pembuatan semen, seperti pada PT. Holcim Indonesia. High chromium white cast iron biasanya diberikan penambahan kromium dari 12-35\% [1]. Namun, penggunaan material ini pada aplikasi industri sedikit rumit. Hal ini dikarenakan sifat ketangguhan dan machinability yang buruk.[2] Penyebab utama dari jenis kegagalan ini adalah dikarenakan timbulnya sejumlah karbida yang bersifat keras dan getas. Karena alasan tersebut, material dengan jenis ini sangat sulit untuk dilakukan pengelasan. Kegagalan yang sering terjadi adalah timbulnya sejumlah cacat las seperti porositas hingga crack pada area weld metal hingga base metal. Oleh karena itu, perlu diadakan penelitian terkait perlakuan panas untuk mereduksi peluang terjadinya kegagalan setelah material dilas. Penelitian ini bertujuan untuk menganalis a pengaruh post weld heat treatment pada material hasil pengelasan ditinjau dari struktur mikro dan kekerasan yang dihasilkan. Penelitian ini dilakukan dengan memberikan perlakuan panas pada variasi temperatur $650^{\circ} \mathrm{C}$ dan $750^{\circ} \mathrm{C}$ dengan variasi waktu tahan selama 1 jam, 2 jam, dan 3 jam.

\section{URAIAN PENELITIAN}

\section{A. Pengujian Komposisi}

Pengujian komposisi bertujuan untuk mengetahui komposisi aktual dari material. Hasil pengujian komposisi yang benar akan membantu dalam menyusun parameter penelitian yang benar pula.

\section{B. Preparasi Spesimen}

Tahap persiapan meliputi pemotongan pelat induk menjadi spesimen pelat dengan ukuran $200 \mathrm{~mm}$ x $100 \mathrm{~mm} \times 10 \mathrm{~mm}$ sebanyak 6 buah. Pelat kemudian dipotong sekaligus membuat profil groove dengan sudut $60^{\circ}$ dengan ukuran $100 \mathrm{~mm} \times 100$ $\mathrm{mm} \times 10 \mathrm{~mm}$.

\section{Proses Pengelasan}

Proses pengelasan dilakukan dengan menggunakan metode SMAW dengan menggunakan arus sebesar $100 \mathrm{~A}$, tegangan 12 volt, dan kecepatan pengelasan sebesar $100 \mathrm{~mm} /$ menit. Pengelasan dilakukan dengan menggunakan filler metal dengan kode AWS $5.15 \mathrm{ENi}-\mathrm{C} 1$ untuk high chromium white cast iron dan AWS 5.1 E7018-H4R untuk bagian baja AISI 1020.

\section{Perlakuan Panas}

Perlakuan panas dilakukan dengan menggunakan muffle furnace di Departemen Teknik Material ITS. 6 buah spesimen pengelasan dipotong menjadi berukuran $70 \mathrm{~mm} \times 100 \mathrm{~mm} \times 10$ $\mathrm{mm}$. Perlakuan panas dilakukan dengan memanaskan material pada dua variasi temperatur yaitu $650^{\circ} \mathrm{C}$ dan $750^{\circ} \mathrm{C}$ dengan waktu tahan 1 jam, 2 jam, dan $3 \mathrm{jam}$. Setelah itu, semua 
material didinginkan dengan kecepatan lambat dengan membiarkan material berada didalam furnace yang telah dimatikan.

\section{E. Pengujian Liquid Dye Penetrant}

Liquid dye penetrant merupakan salah satu jenis pengujian tanpa merusak. Pengujian ini dilakukan untuk melihat ada tidaknya cacat yang ditimbulkan dari hasil pengelasan pada permukaan logam hasil pengelasan. Pengujian dilakukan dengan menggunakan cairan penetrant, cleaner, dan developer. Pertama, cairan penetrant disemprotkan pada bagian permukaan lasan lalu kemudian ditunggu selama 10 menit. Setelah itu, cleaner diaplikasikan pada bagian permukaan material untuk membersihkan sisa penetrant. Terakhir, cairan developer dengan warna putih diaplikasikan untuk menarik penetrant dari indikasi cacat.

\section{F. Pengujian Metalografi}

Setelah perlakuan panas, spesimen kemudian dibersihkan dari oksida yang menempel dengan menggunakan gerinda. Spesimen kemudian dihaluskan dengan menggunakan kertas amplas dengan grade 80, 120, 320, 600, 1000, 1500, dan 2000. Setelah diamplas, material kemudian diberikan metal polish agar permukaannya mengkilap sekaligus menghilangkan goresan sis a pada material. Material kemudian direndam dalam larutan etsa nittal dengan komposisi $5 \mathrm{ml}$ $\mathrm{HNO}_{3}$ dan $95 \mathrm{ml}$ alkohol dengan waktu rendam sebesar 2 menit untuk pengetasaan. Tujuan dari pengetsaan adalah untuk membuat butir dan batas butir terkorosi. Hal ini akan menimmbulkan perbedaan wilayah gelap dan terang pada struktur mikro. Setelah dilakukan pengetsaan, material kemudian diamati dibawah mikroskop untuk melihat apa saja fasa yang terbentuk berdasarkan perbedaan kecerahan permukaan hasil pengetsaan.

\section{G. Pengujian Kekerasan}

Pengujian kekerasan dilakukan untuk mendapatkan nilai kekerasan. Pengujian dilakukan dengan menggunakan metode Vickers. Pengujian ini menggunakan beban sebesar $100 \mathrm{kgf}$ dengan waktu indentasi 10 detik. Pengujian kekerasan dilakukan untuk menguji nilai kekerasan di 3 daerah hasil pengelasan yag meliputi weld metal, HAZ, dan base metal. Pada tiap daerah, dilakukan indentasi sebanyak 4 kali pada titik yang berbeda. Hasil indentasi kemudian diamati dibawah mikroskop dan dengan menggunakan bantuan komputer, kekerasan material dapat tampil di layar.

\section{HASIL DAN DISKUSI}

\section{A. Pengujian Komposisi}

Dari hasil pengujian komposisi terhadap material hasil cladding, didapat hasil berupa

Tabel 1.

Komposisi material high chromium white cast iron

\begin{tabular}{ccccccc}
\hline \hline Material & \multicolumn{7}{c}{ Komposisi(\%massa) } \\
\hline $\begin{array}{c}\text { High } \\
\text { Chromium } \\
\begin{array}{c}\text { White Cast } \\
\text { Iron }\end{array}\end{array}$ & $\mathrm{C}$ & $\mathrm{Cr}$ & $\mathrm{Mo}$ & $\mathrm{V}$ & $\mathrm{Ti}$ & $\mathrm{Si}$ \\
\cline { 2 - 7 } & 2,29 & 12,72 & 0,02 & 0,072 & 0,031 & 0,231 \\
\hline \hline
\end{tabular}

Tabel 2.

Komposisi Material AISI 1020

\begin{tabular}{ccccccc}
\hline \hline Material & \multicolumn{7}{c}{ Komposisi(\%massa) } \\
\hline Baja AISI & $\mathrm{C}$ & $\mathrm{Si}$ & $\mathrm{Mn}$ & $\mathrm{P}$ & $\mathrm{S}$ & $\mathrm{Cr}$ \\
\cline { 2 - 7 } 1020 & 0,19 & 0,15 & 0,26 & 0,0226 & 0,018 & 0,0157 \\
\hline \hline
\end{tabular}

\section{B. Pengujian Liquid Dye Penetrant}

Pengujian dengan menggunakan liquid dye penetrant menemukan cacat pada hasil pengelasan berupa porositas dan ada hampir pada semua material ditemukan adanya false indication cacat undercut. Kemudian hal itu dikonfirmasi sebagai cairan penetrant yang meluber ke bagian weld metal karena dimensi spesimen hasil pengelasan yang mengalami distorsi sebagai akibat adanya thermal stress akibat pendinginan setelah pengelasan.

\section{Pengujian Struktur Mikro}

Proses pemanasan 6 spesimen hasil pengelasan pada temperatur $650^{\circ} \mathrm{C}$ dan $750^{\circ} \mathrm{C}$ dengan variasi waktu tahan 1 jam, 2 jam, dan 3 jam menunjukkan hasil pada struktur mikro menunjukkan adanya fas a berupa solid solution $\gamma$-Nickel pada daerah weld metal. Pada daerah heat affected zone ditemukan struktur mikro berupa perlit dan karbida. Pada daerah base metal, ditemukanfasa yang sama dengan daerah HAZ, dimana fasa yang terbentuk adalah karbida dan struktur perlit dan karbida.
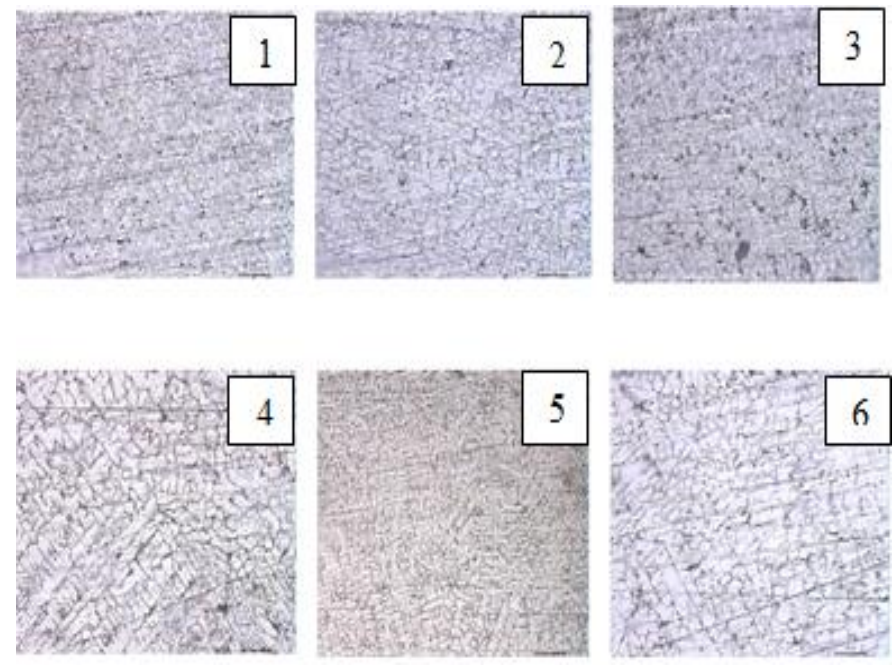

Gambar 1. Weld Metal 200x

\section{$\underline{1}: 650^{\circ} \mathrm{C}-1$ Jam $\underline{2}: 6^{\circ} 0^{\circ} \mathrm{C}-2 \operatorname{Jam} \underline{3}: 650^{\circ} \mathrm{C}-3 \mathrm{Jam} \underline{4}: 7^{\circ} 0^{\circ} \mathrm{C}-1 \mathrm{Jam} \underline{5}:$ $7_{50}^{\circ} \mathrm{C}-2$ Jam $\underline{6}: 7^{\circ} 0^{\circ} \mathrm{C}-3 \mathrm{Jam}$}

Fasa yang terjadi pada weld metal berupa larutan padat antara Ni dan Fe dan antara Ni dengan Ti [3]. Jenis larutan padat yang terbentuk berupa larutan padat substitusional. 

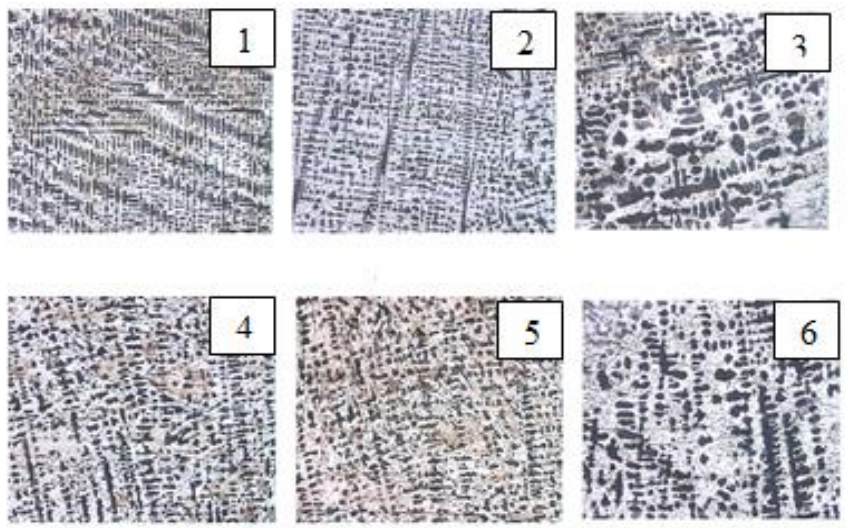

Gambar 2. HAZ 200x

\section{$\underline{1}: 650^{\circ} \mathrm{C}-1$ Jam $\underline{2}: 6^{\circ} 0^{\circ} \mathrm{C}-2 \operatorname{Jam} \underline{3}: 650^{\circ} \mathrm{C}-3 \mathrm{Jam} \underline{4}: 7^{\circ} 0^{\circ} \mathrm{C}-1$ Jam $\underline{5}:$ $750^{\circ} \mathrm{C}-2$ Jam $\underline{6}: 7^{\circ} \mathrm{C}-3 \mathrm{Jam}$}

Pada gambar 2, struktur mikro yang terbentuk di daerah HAZ adalah struktur perlit (daerah gelap) dan karbida(daerah terang). Pada holding temperature sebesar $650^{\circ} \mathrm{C}$, terlihat bahwa kenaikan wktu tahan akan menghasilkan perlit dengan ukuran semakin kasar pula. Pada temperatur sebesar $750^{\circ} \mathrm{C}$, kenaikan waktu tahan juga akan membuat ukuran perlit menjadi kasar.
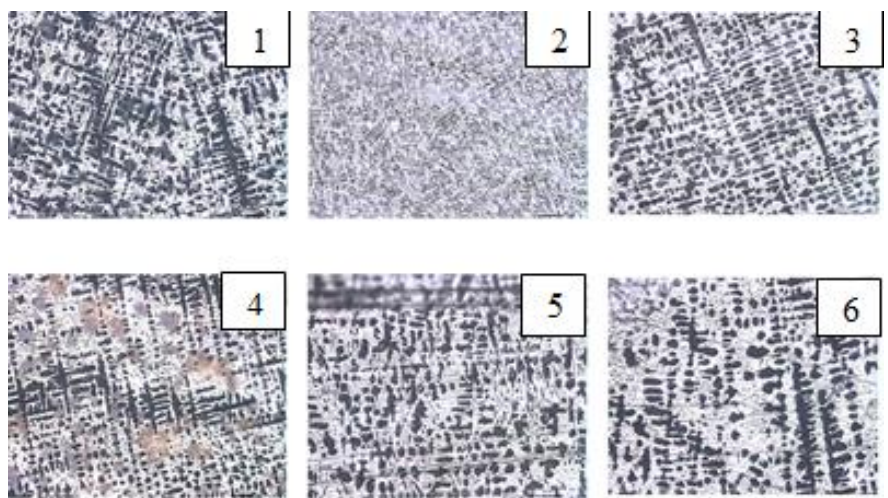

Gambar 3. Base Metal 200x

\section{$\underline{1}: 650^{\circ} \mathrm{C}-1$ Jam $\underline{2}: 6^{\circ} 0^{\circ} \mathrm{C}-2$ Jam $\underline{3}: 650^{\circ} \mathrm{C}-3 \mathrm{Jam} \underline{4}: 7^{\circ} 0^{\circ} \mathrm{C}-1$ Jam $\underline{5}:$} $750^{\circ} \mathrm{C}-2$ Jam 6: $750^{\circ} \mathrm{C}-3 \mathrm{Jam}$

Pada gambar 3 , terlihat struktur mikro yang terbentuk pada daerah base metal sama seperti pada $H A Z$, yaitu struktur perlit dan karbida. Pada holding temperature sebesar $650^{\circ} \mathrm{C}$ dengan waktu tahan 1 jam, gambar 3 poin 1 , menunujukkan adanya pertumbuhan perlit yang tebal namun tidak memutus kontinuitas karbida. Pada waktu tahan sebesar 2 jam, gambar 3 poin 2, perlit yang terbentuk memiliki morfologi equaixed dan karbida menyambung secara kontinu. Pada waktu tahan 3 jam pada temperatur $750^{\circ} \mathrm{C}$, gambar 3 poin 3 , struktur perlit tumbuh dengan sangat hebat.

\section{Pengujian Kekerasan}

Pengujian kekerasan yang dilakukan pada 6 spesimen pengujian dengan 3 daerah pengujian, yaitu weld metal secara keseluruhan menunjukkan nilai kekerasan terendah. Nilai kekerasan pada daerah HAZ dan base metal menunjukkan nilai yang tinggi.

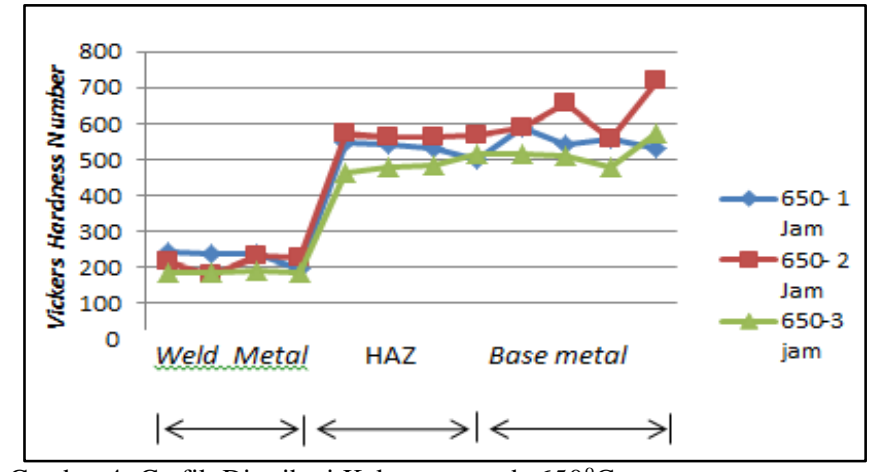

Gambar 4. Grafik Distribusi Kekerasan pada $650^{\circ} \mathrm{C}$

Pada Gambar 4, kekerasan terendah dicapai oleh weld metal. Nilai kekerasan yang rendah pada weld metal disebabkan oleh bentuk penguatan berupa solid solution strengthening yang lebih rendah dibanding penguatan melalui kemunculan senyawa karbida. Selain itu, jenis penguatan berupa subtitutional solid solution juga berpengaruh pada nilai kekerasan yang rendah. [4].

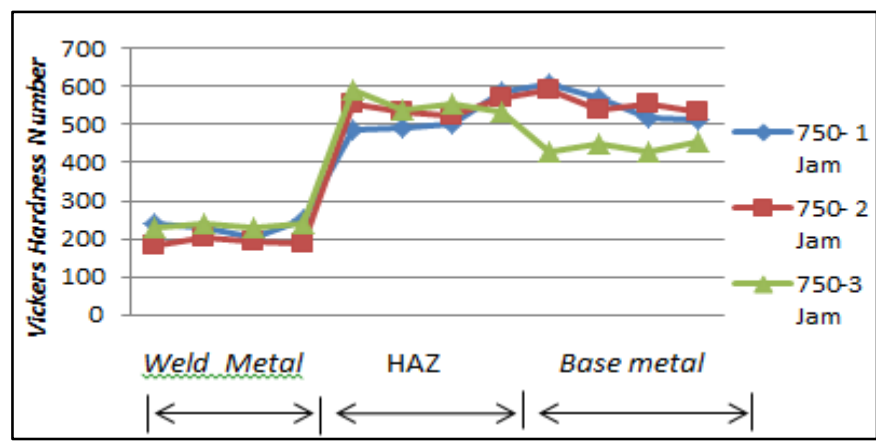

Gambar 5. Grafik Distribusi Kekerasan pada $750^{\circ} \mathrm{C}$

Pada Gambar 4, HAZ dengan pemanasan $650^{\circ} \mathrm{C}$, kekerasan yang dicapai oleh material dengan perlakuan panas 2 jam memiliki tingkat kekerasan tertinggi. Hal ini sangat dimungkinkan melihat struktur dari perlit yang terputus - putus sehingga tidak kontinu. Oleh karena itu, menyebabkan presipitat karbida membentuk network yang kemudian akan menambah kekerasan dari material. Pada gambar 5, perlakuan panas pada temperatur $750^{\circ} \mathrm{C}$, dengan waktu tahan sebesar 2 jam, kekerasan HAZ merupakan yang tertinggi. Hal ini dikarenakan pada beberapa daerah dijumpai struktur carbide network dan berbentuk lath. Bentuk ini akan menambah kekerasan pada logam. [5]. Kekerasan pada waktu tahan 3 jam menunjukkan penurunan kekerasan pada kedua waktu pemanasan. Hal ini dimungkinkan akibat semakin membesarnya struktur perlit dan semakin karbida mengalami degradasi morfologi [6]. Pada temperatur yang sama dengan waktu tahan selama 1 jam, kekerasan daerah HAZ menurun. Hal ini terjadi akibat degradasi bentuk karbida setelah pemanasan. Pada waktu tahan 3 jam, kekerasan pada daerah HAZ menurun jauh. Hal ini kemudian penulis konfirmasi melalui pengamatan mikro struktur dimana ukuran perlit yang dihasilkan bertambah tebal dan karbida primer terdegradasi dengan intensitas yang besar. 
Pada Gambar 4 bagian base metal, kekerasan tertinggi dicapai pada holding time 2 jam dengan temperatur pemanas an $650^{\circ} \mathrm{C}$. Nilai ini tidak jauh berbeda dengan holding time 1 jam. Kekerasan dapat dipertahankan dengan sangat baik dikarenakan banyak terdapat struktur lath carbide network yang terjadi dan daerah perlit yang terbentuk menunjukkan struktur yang tidak kontinu. Sebagai akibatnya, jaringan karbida yang terbentuk semakin luas dan kontinu. Kekerasan pada bagian base metal yang terendah ditunjukkan oleh perlakuan panas dengan holding time 3 jam pada temperatur $750^{\circ} \mathrm{C}$, Gambar 5. Penurunan kekerasan yang sangat besar diakibatkan oleh pertumbuhan perlit yang semakin besar sebagai akibat semakin banyaknya karbon yang keluar ke batas butir ferit dengan semakin lamanya waktu holding.

\section{KESIMPULAN}

Dari penelitian yang telah dilakukan, didapat beberapa kesimpulan yaitu :

1. Struktur Mikro yang didapat setelah dilakukan perlakuan panas secara umum adalah berupa $\gamma$ Nickel pada daerah weld metal . Pada daerah HAZ dan base metal struktur mikro yang diamati adalah perlit dan dua karbida yang terbentuk setelah melewati garis eutektik dan eutektoid.

2. Kekerasan pada weld metal merupakan yang terendah. Hal ini dikarenakan bentuk penguatan secara larutan padat substitusional. kekeras an pada bagian HAZ dan base metal yang tertinggi dicapai pada waktu tahan 2 jam untuk kedua variasi. Penurunan kekerasan terjadi pada daerah HAZ dan base metal dengan waktu tahan 3 jam. Penurunan kekerasan disebabkan oleh beberapa hal yaitu terbentuknya fasa perlit, karbida yang tidak kontinu, dan adanya degradasi karbida dengan semakin lamanya waktu tahan dan pendinginan pada proses annealing.

\section{DAFTAR PUSTAKA}

[1] F. J. B. P Fernandez, "Wear and oxidation behavior of highchromium white cast irons," J. Mater. Charact., vol. 6, pp. 669674, 2013.

[2] M. . D. L. M.M Jansen, "Fracture toughness of high chromium white cast iron in relation to the primary carbide morphology," in Proc. 13 th European Conference on Fracture, 2008.

[3] J. . K. G Gacciamini, "Critical Evaluation of the Fe-Ni, Fe-Ti, and Fe-Ni-Ti Alloy Systems,” vol. 14, pp. 10-11, 2005.

[4] R. W.. Bhadesia, H.K.D.H., Honeycombe, Steels: Microstructures and Its Property. UK: Butterworth-Heinemann, 2006.

[5] D. S. D. Kopyciński, E. Guzik, "Analysis of the High Chromium Cast Iron Microstructure after theHeat Treatment," Foundry Eng., vol. 3, p. 43, 2014.

[6] A. L. E. Karantzalis, "icrostructure and properties of high chromium cast irons: effect of heat treatments and alloying additions," $J$. Mater. Eng. Perform., vol. 2, pp. 451-452, 2013. 